\title{
Biopsychosocial effects of training in recognition, emotional facial reproduction and relaxation: A pilot study
}

\author{
David A. Rodríguez ${ }^{1,2}$, Benjamín Domínguez ${ }^{3}$, Gerardo Leija ${ }^{4}$, M. Rocío Hernández ${ }^{3}$ and Leticia G. Ríos ${ }^{5}$ \\ ${ }^{1}$ Universidad Autónoma Metropolitana, Iztapalapa, México \\ ${ }^{2}$ Universidad Autónoma de Querétaro, Querétaro, México \\ ${ }^{3}$ Universidad Nacional Autónoma de México, México \\ ${ }^{4}$ Instituto Politécnico Nacional, México \\ ${ }^{5}$ Universidad Autónoma de Ciudad Juárez, Ciudad Juárez, México
}

\begin{abstract}
Several studies have evaluated emotional facial recognition in people with neurological disorders and psychiatric illnesses. However, few behavioral rehabilitation programs in social skills include training in emotional facial recognition and reproduction. The objective of the present investigation was to develop a pilot brief intervention in recognition and emotional facial reproduction and its deactivation through relaxation, to evaluate its biopsychosocial effects. A pre - post-treatment design was used ( $N=22$ healthy adults). The results have shown an effect on the decrease of the respiratory rate $(p<.001)$ and the inflammatory response associated with stress $(p<.05)$, as well as a decrease $(p<.05)$ of the anxiety score, depression and emotional suppression; and an increase in the social support score. Its clinical utility is discussed in the context of training these skills for mental health professionals and patients with elevated inflammation.
\end{abstract}

Keywords: Expression-facial-emotional; IL-6; social support; suppression emotional; depression; anxiety; relaxation.

Efectos biopsicosociales del entrenamiento en reconocimiento, reproducción facial emocional y relajación: Un estudio piloto

Resumen: Diversos estudios han evaluado el reconocimiento facial emocional en personas con transtornos neurológicos y enfermedades psiquiátricas. Sin embargo, pocos programas de rehabilitación conductual en habilidades sociales incluyen el entrenamiento en reconocimiento y reproducción facial emocional. El objetivo de la presente investigación fue desarrollar una intervención breve piloto en reconocimiento y reproducción facial emocional y su desactivación mediante la relajación, para evaluar sus efectos biopsicosociales. Se utilizó un diseño pre - post tratamiento ( $N=22$ adultos sanos). Los resultados muestran un efecto sobre la disminución de la tasa respiratoria $(p<.001)$ y la respuesta inflamatoria de asociada con estrés $(p<.05)$, así como un decremento $(p<.05)$ del puntaje de ansiedad, depresión y supresión emocional; y un incremento en el puntaje de apoyo social. Su utilidad clínica se discute en el contexto de entrenar estas habilidades para los profesionales en salud mental y en pacientes con inflamación elevada.

Palabras Clave: Expresión-facial-emocional, IL-6, apoyo-social, supresión-emocional, depresión, ansiedad, relajación.

\section{Introduction}

One of the most relevant aspects of human social interaction is the ability to infer others' mental states and

Recibido: 6 de marzo 2019; aceptado: 27 de febrero 2020.

Correspondencia: David Alberto Rodríguez. Av. San Rafael Atlixco 186, Leyes de Reforma 1ra Sección, 09340. Cubículo 103, Edificio H, Universidad Autónoma Metropolitana, Unidad Iztapalapa. México. Correo-e: psic.d.rodriguez@comunidad.unam.mx. emotions. To establish emotional connection between species, one way is through facial (and corporal) mimicry, which allows us to recognize the affective state and enable empathic capacity. Its implications have important effects for emotional health, social support, and feelings of affiliation (Prochazkova \& Kret, 2017).

By combining different facial muscle actions, called action units (AUs), humans can produce an extraordinarily large amount of facial expressions (Srinivasan, Golomb, \& Martinez, 2016). Accurate 
recognition of these emotional facial expression is a non-verbal social skills (Chóliz \& Fernández-Abascal, 2012). In order to evaluate facial expression, Ekman and Friesen (2002; in Cohn, Ambadar, \& Ekman, 2007) developed the Facial Action Coding System (FACS) derived from their research in diverse cultures, where they found that some emotions share equivalent facial movements.

A neurophysiological theory of social behavior is the polyvagal theory (PT) (Porges, 2001; Porges, 2003), which argues that autonomous dominance will facilitate specific affective behavior and related feelings. In particular, the PT suggests three levels of physiological activation: 1) Immobilization, which keeps energy expenditure to a minimum for survival, including a distancing from social contact, and in particular, a decrease in emotional facial expression, between other effects; 2) Fight/flight, in which the organism prepares the physiological resources to face the stressor, and whose facial expression appears and accompanies the emotion that the individual experiences (fear or angry, for example); 3) Social Engagement, in which physiological activation is low, facilitating social interaction behaviors, promoting emotional facial gesticulation of serenity.

Some neurological diseases (Gola et al., 2017; Ricciardi et al., 2017) and psychiatric, such people with anxious spectrum and mood disorders (depression) (Berg et al., 2016; Shiroma, Thuras, Johns, \& Lim, 2016) affect performance to recognize emotions and have difficulty regulating their autonomic affective functioning and social involvement behaviors (emotional facial expression and control of striated muscles of the face and head reduced) (Porges, 2003). Stress (physical or emotional) can influence emotional regulation activing three systems:, nervous system (central, peripheral autonomic and somatic - and enteric gastrointestinal); endocrinological system; immune system, in particular, proinflammatory cytokines, such as interleukins (IL) (Liu, Wang, \& Jiang, 2017). Although these cytokines are beneficial for short-term inflammation, long-term chronic inflammation is detrimental (Hunter, 2015). Interleukin 6 has positioned itself as a biomarker of inflammation, acute stress (Carpenter et al., 2010; Koelsch et al., 2016), psychosocial stress (Quinn, Williams, Sivilli, Raison, \& Pace, 2018), anxiety (Lazaridou et al., 2018), depression (Voorhees et al., 2013), fatigue (Rohleder, Aringer, \& Boentert, 2012), among others.

Functionallity recognition of emotional facial expression be altered by the immunological activity of pro-inflammatory cytokines as IL-6, (Moieni, Irwin, Jevtic, Breen, \& Eisenberger, 2015). The IL-6 communicates with the peripheral systems and the central nervous system, particularly with the anterior cingulate cortex (CCA) which analyses the valence of the emotional stimuli (Bollen, Trick, Llewellyn, \& Dickens, 2017), so a high concentration of IL-6 may impair with the recognition of emotional facial expression.

The recognition of facial expression is a social skill that can be trained through simulation (voluntary and sustained behavior of facial behavior) and mentalization (the cognitive process of inferring the mental and affective state of other people from their behaviors, gestures, expressions and body postures and/or vocal intonations of verbal discourse under a particular social context, to decode the intentions of other people and adapt or modify one's behavior) (Conson et al., 2013). During the execution of a person's emotional facial expression, the same facial muscles are activated in an observer (Dimberg et al., 2000).

In Mexico, a reliable study have been conducted on the ability of emotional facial recognition on university students (Arango, Millin, Brüne, \& Muñoz, 2014). However, in none of them there is a promoted program to strenghten this skill. Several studies have evaluated the effect of voluntary emotional facial expression on psychophysiological reactions (Levenson, Ekman, \& Friesen, 1990; Price, \& Harmon, 2015). These investigations suggest that manipulation of facial expressions and some body postures influence not only physiological reactions (heart rate, temperature), but subjective sensations and cognitive processes, such as reaction time in which they classify and decode affective stimuli (Price \& Harmon, 2015).

Although there are some emotional regulation programs (Shafir, 2015), there are few neurological rehabilitation programs that have used the reproduction of emotional facial expression as part of social skills training. A behavioral method to develop the recognition and voluntary expression of basic emotions, through changes in posture and breathing patterns, is the Alba Emoting TM, which has been applied to train the actors, as well as a clinical use to facilitate recognition and emotional regulation (Kalawski, 2013). However, although it is based on respiratory patterns to simulate a basic emotional configuration, including facial expression, it is still necessary to evaluate its effects on the respiratory rate at the end of the training. Its clinical and academic utility has not been promoted into the university programs of undergraduate and postgraduate as a clinical tool for the management of emotional regulation of various disorders associated with stress. The basis of Alba Emoting TM training is respiratory control. The facial simulation procedure should be similar for the distinction between an affective state 
and calm: tension-facial relaxation. The latter can be regulated by respiratory control.

The present pre-clinical study had the following objectives: 1) To assess the effect of training on emotional facial recognition and reproduction and relaxation on ability in recognition in emotional facial expression valued by the number of mistakes made in an emotional facial recognition test. 2) To assess the biopsychosocial effects associated with pre-post intervention stress on somatic response and inflammatory activity, the selfreport of anxiety, depression, social support, alexithymia, and emotional regulation.

\section{Method}

\section{Participants}

We requested the voluntary participation of 22 undergraduate and graduate university students, with an age $M=25.2$ years ( $S D=6.8$ years), $50 \%$ women. The participants were recruited through a verbal public announcement in the classrooms of pre-degrade Psychology students o to participate voluntarily in the protocol. All participants signed their informed consent based on the Helsinki declaration.

\section{Research design}

For the salivary collection of IL- 6 and the psychometric measurements we used a pre-post intervention design, while a repeated measures design was used to evaluate the respiratory rate during the intervention. Figure 1 presents the diagram of the biopsychosocial evaluation protocol.

\section{Materials and instruments}

Interleukin 6 salivary (IL-6). A salivary sample of the pro-inflammatory cytokine IL- 6 was collected and obtained according to the instructions of the manufacturer Sarstedt, Newton, NC, and was centrifuged at $3000 \mathrm{rpm}$ for $15 \mathrm{~min}$. The concentration of IL-6 was determined by an ELISA kit, based on the instructions of the manufacturer Salimetrics State College PA, at a dilution of 1:5. The concentrations of IL-6 were determined using a luminance counter at $450 \mathrm{~nm}$ with a secondary filter from 620 to $630 \mathrm{~nm}$. A standard adjustment curve of the concentrations of IL- 6 of each participant was obtained with an adjustment of $R^{2}=0.98$ (procedure used to determine the concentration of IL- 6 by the ELISA test, according to the Salimetrics State College PA depending on the concentration of the biomarker and the absorbance).

Beck's Anxiety Inventory (BAI). It is a short selfreport measure to determine the level of anxiety, with a Likert-type scale of 0 to 3 . It has excellent psychometric properties validated in Mexico (Robles, Varela, Jurado, \& Páez, 2001).

Beck's Depression Inventory (BDI). It is a short selfreport measure to determine the level of depression, with a Likert-type scale of 0 to 3 . It has excellent psychometric properties validated in Mexico (Jurado, Villegas, Méndez, Rodríguez, Loperena, \& Varela, 1988).

Toronto Alexithymia Scale. This is the most widely used scale for the evaluation of Alexithymia; however, there are different versions according to the objective of the research and study sample. Its original version (Taylor, Ryan, \& Bagby, 1985; quoted in Durán, 2007)

\section{Training in emotional facial recognition, voluntary emotional facial expression and relaxation}

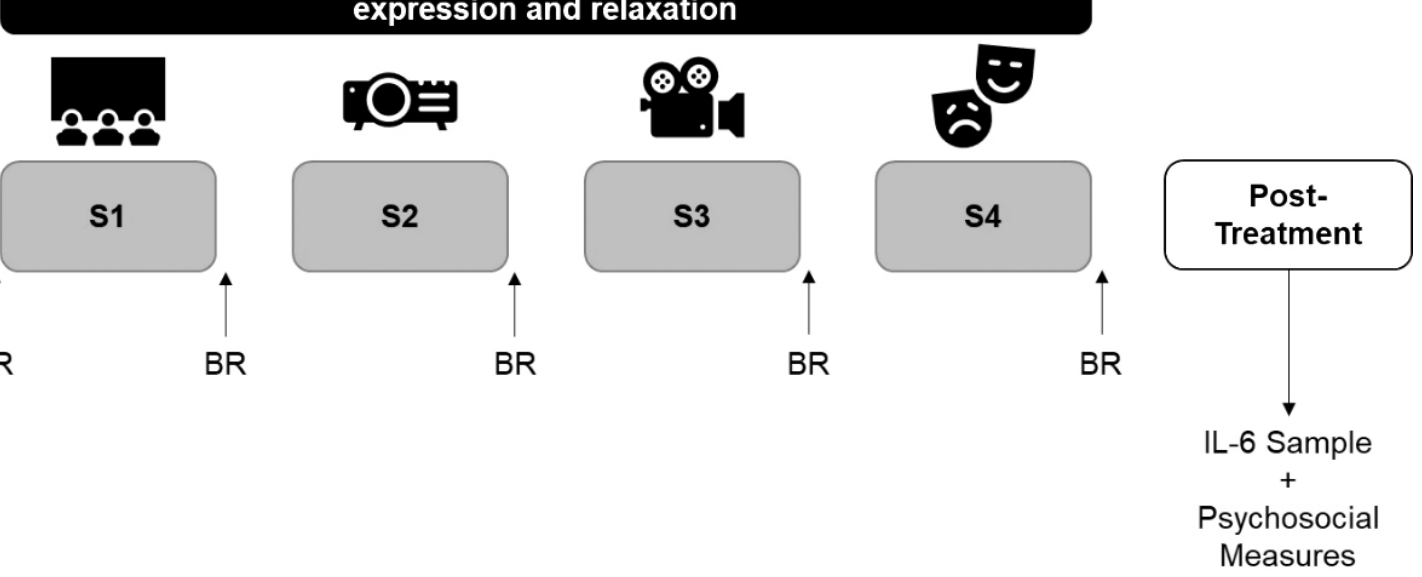

Figure 1. Research design. 3IL-6 = interleukin 6 salivary sample; $\mathrm{BR}=$ Breathing Rate; $\mathrm{S} 1=\mathrm{Session} 1 ; \mathrm{S} 2=\mathrm{Session} 2$; $\mathrm{S} 3=\mathrm{Session} 3$; $\mathrm{S} 4=$ Session. 
consisted of 20 items grouped into three factors; however, a short version has been validated in university students in Mexico, (Durán, 2007), wich includes only 10 items grouped into two factors: difficulty expressing feelings and difficulty in identifying feelings.

Emotional Regulation Questionnaire (EQR). The Spanish version of EQR (Cabello, Salguero, Fernandez, \& Gross, 2013), has good psychometric properties. It consists of a scale of 10 Likert-type reagents, divided into 2 factors: Cognitive Reassessment and Emotional Suppression.

Scale and Social support family and Friends (SSSF\&F). A scale Likert type with 20 items, it values the social support of family and friends performed in Mexican's University population (González, Ramírez, \& Hernández, 2014).

FACS. For the training of the reproduction of the facial behavior were used the units of Action (AU) of the FACS that make up the facial configuration prototypical (Domínguez-Sánchez, 2010) of 6 Emotions: Joy (AU6 + AU12 + AU25), sadness (AU1 + AU4 + AU15 + AU17), anger (AU4 + AU5 + AU7 + AU17 + AU23 + AU24 + AU38), fear (AU1 + AU4 + AU12 + AU20 + 25), disgust (AU4 + AU6 + + AU9 + AU17) and surprise (AU1 + $\mathrm{AU} 2+\mathrm{AU} 5+\mathrm{AU} 25+\mathrm{AU} 27)$.

FEEL TEST. It consists of the presentation of 42 photographs with emotional faces based on the FACS, with a presentation of $3000 \mathrm{~ms}$ duration. The participant must choose the name of the emotion that corresponds to the emotional facial expression (Kessler, Bayerl, Deighton, \& Traue, 2002).

$B E-F A C E$. It is a bank of photographs of Mexican people with emotional facial expressions with experimentally validated with the FACS (Morales, Lopez, \& Hedlefs, 2010).

Diaphragmatic respiration. An EmWave ${ }^{\circledR}$ (Pro) Biofeedback equipment software exercise from the Heart Math company was used. Its use promotes a respiratory rate of 12 cycles (inhalation-exhalation) per minute or less by visually following the movement of a sphere that takes a top-down path projected in a video. The subject must inhale when the sphere ascends to the highest point, and subsequently, it must exhale slowly and deeply when the sphere travels downward. To perform this exercise, the subjects were asked to remain seated, free of any object in the body, with their backs resting on the back of the chair. For 1 minute they visually followed the projection of a video in which the sphere appeared to induce a slow breathing rate and synchronized their breathing rate, and subsequently, they were asked to close their eyes in order to continue performing diaphragmatic breathing: slow, deep and soft.
Video clips. We used videos of people with spontaneous emotional reactions with ecological validity extracted from the Internet channel YouTube, Just for laughs to reinforce the knowledge of the facial movements associated with an emotion. An expert psychologist in the detection of emotional facial expression rated the videos to validate the different emotional expressions, based on the FACS. Six videos were used, with an approximate duration of 01:30 min each, for each emotion to be trained for recognition and facial reproduction.

\section{Procedure}

The psychological evaluation and intervention were grouped and performed for one week: two pre-and post-treatment sessions where the psychological scales applied, the emotional facial recognition test (FEEL test) and the salivary sample of IL- 6 were collected between 09:00 and 09:30 hours. The proposed treatment for recognition and simulated emotional facial expression consisted of four weekly sessions, for 1 hour. The protocol was as follows (see Figure 1):

1. Psychoeducation session, in order to explain the clinical importance of learning non-verbal social skills into the recognition of emotional control. During this session we presented similar research data about recognition of emotional facial expression in resident physicians of psychiatry at the beginning of their postgraduate and follow-up 3 years after their medical training on the accuracy of facial recognition, to establish that this skill Social non-verbal can be trained in a shorter time than 3 years. Likewise, the relationship between emotional facial expression and their respiratory patterns was established. This was achieved by displaying the different emotional facial expressions to examine their facial movements supported by the FACS and their effect on breathing: some gestures promote rhythmic breathing, while other facial movements, for example, those that make up the expression of fear, make natural breathing difficult.; and how diaphragmatic breathing (less than 12 breaths per minute) can induce a low respiratory rate, which decreases facial muscle tension, facilitating an affective state of relaxation. The respiratory rate was recorded before the session and once it was over, the first diaphragmatic respiration exercise was provided in order to register the respiratory rate of each participant.

2. Training session in facial expression recognition, which showed the AU of each emotion through the 
photographs of the BE-FACE. Then the video clips of each emotion were used to visualize the movements in real time. The last 10 minutes, a diaphragmatic respiration training was given

3. Session of emotional expression consisted in the presentation of an emotional photograph of the BEFACE and its facial imitation. It was subsequently requested to voluntarily maintain the facial expression for 10 seconds to subjectively experience that emotion. Due to the respiratory changes that are generated to maintain each facial movement, the last 10 minutes were destined to the training of the diaphragmatic respiration.

4. Emotional video clips were shown, and participants were instructed to perform the AUs of each facial expression and to maintain them for 10 seconds and verbally indicate the emotion experienced by the subject. At the end of the session we asked them to carry out the diaphragmatic respiration by themselves.

\section{Statistical analysis}

To perform the statistical analysis, the SPSS software, V.21.0, was used (SPSS, Inc., Chicago, IL, U.S.A.). Data normality was explored by the Shapiro-Wilk Statistics test ( $p>.05)$ where no normal pre-treatment distribution $(p<.001)$ or post-treatment $(p=.008)$ was found in the concentration of salivary IL- 6 , therefore, the effect of the treatment on IL-6 was compared using a Wilcoxon test. An ANOVA of repeated measurements (with a factor, session, intrasubject) was used for the training sessions in diaphragmatic respiration. A Pearson correlation was obtained between the psychosocial measures, as well as between the errors and the concentration of IL-6. A student $t$ was applied for related samples to evaluate the pre-post treatment effect of each measure an $\alpha=.05$ was established to evaluate the significance. Additionally, the size of the effect of each measure was obtained using the Cohen $d$, or the $r$ value of according with the statistical test used.

\section{Results}

Psychophysiological effects: Respiratory rate and IL-6.

Training in emotional facial reproduction and muscle deactivation by diaphragmatic respiration session revealed a significant reduction in respiratory rate $(F(4,20)=10.55, p<.001, d=1.01)$. We also found a significant decrease in the cytokine IL-6 salivary prepost treatment $(Z=-2,040, p=.041$, with an effect size $r=.416$ ) (Figure 2).

\section{Behavioral effect}

The concentration of IL- 6 pre-treatment showed a significant relationship $(r=.703, p=.008)$ with the number of errors of the facial recognition FEEL test. The training in facial recognition and reproduction had a significant effect in reducing the number of errors made on the emotional facial recognition of the FEEL test $(Z=-3,185, p=.001, r=.563$ ) (Figure 3). Scores on errors that decreased significantly in recognition of emotional
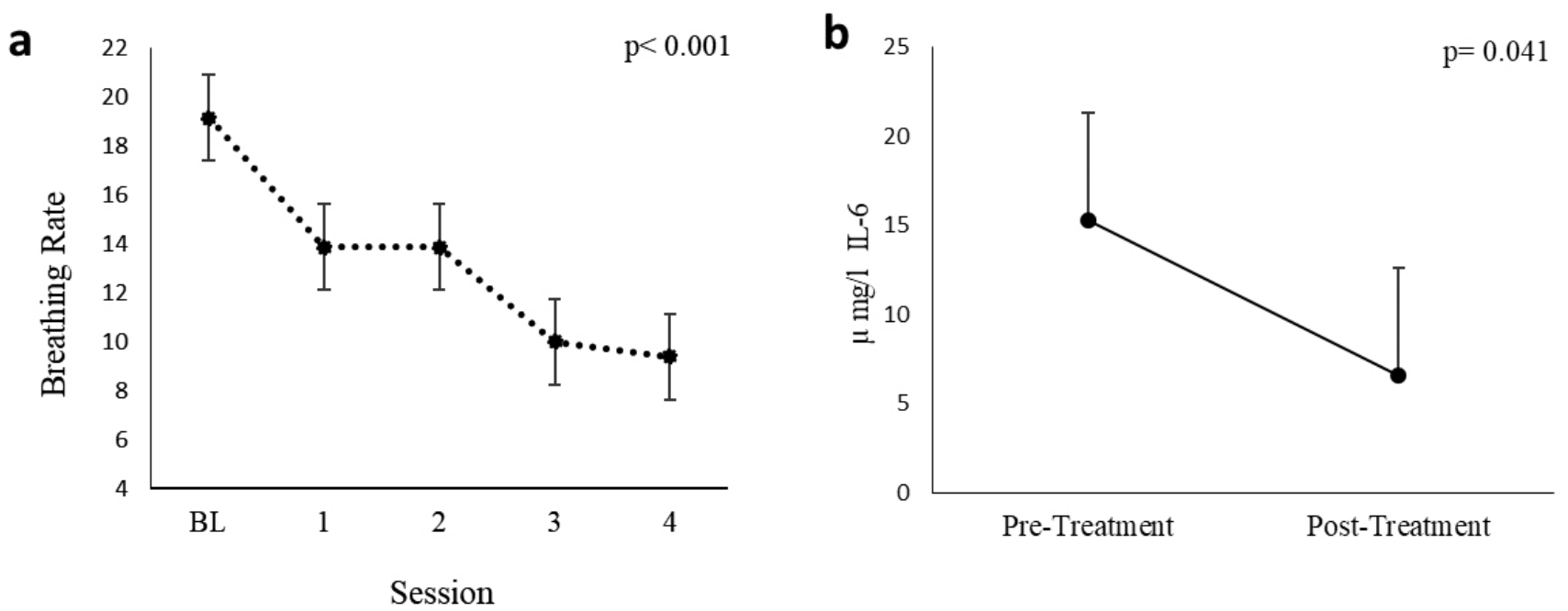

Figure 2. Effects of treatment on somatic activity and inflammatory response. Experimental approach. (a) Effect of training in diaphragmatic breathing on the respiratory rate. (b) Pre-post treatment effect on salivary IL-6 showed a significant decrease. Standard error bars are presented. $\mathrm{BL}=$ baseline. 
facial expression decreased pre-post treatment. They were: Fear $(Z=-3,320, p<.001, r=.587)$, and Disgust $(Z=-2,648, p=.008, r=.468)$. The decrease in the errors of recognition of facial expressions of anger, joy, surprise and sadness showed no statistically significant effect $(p>.05)$.

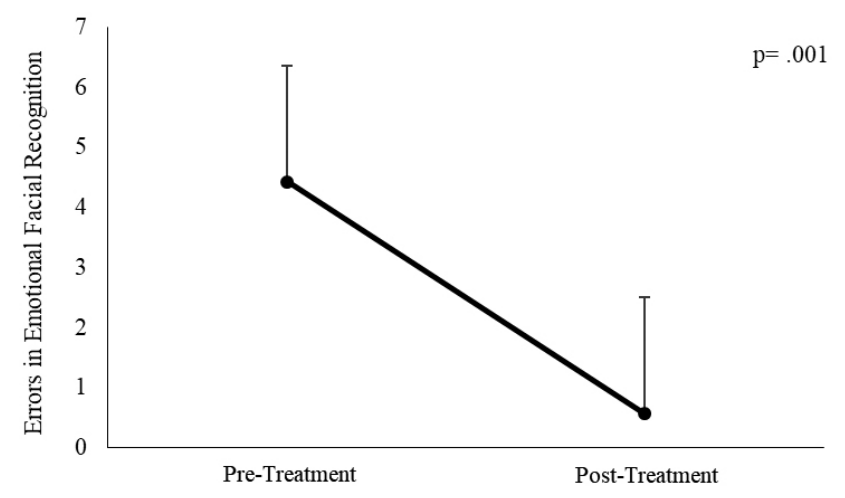

Figure 3. Effects of treatment on errors in facial emotional recognition.

Errors in the emotional facial expression recognition test FEEL TEST pre-post treatment. Standard error bars are presented.

\section{Psychosocial effects}

Pre-treatment psychosocial evaluation indicated that $20 \%$ of the sample showed a moderate level of anxiety, while $53 \%$ showed a mild level of anxiety and $27 \%$ shows no anxiety. Depression levels indicate that $6 \%$ maintain a moderate level; $27 \%$ have mild depression and $67 \%$ do not show depression. Pre-post treatment in the scores of anxiety, depression, social support and emotional suppression, which decreased significantly (Table 1). Additionally, we found some correlations between psychosocial measures pre-treatment: The score of anxiety with the difficulty of emotional expression of Alexithymia $(r=.621, p=.014)$ and the score of depression $(r=.656, p=.008)$; The depression score with the difficulty of identifying Alexithymia's own emotions $(r=.575, p=.025)$, with the difficulty of emotional expression of Alexithymia $(r=.678, p=.005)$, with the total score of Alexithymia $(r=.688, p=.005)$, and an inverse relationship with the Family Social support Score $(r=-.657, p=.008)$. The social support score had a negative relationship with Alexithymia's emotional expression difficulty scores $(r=-.53, p=.042)$, difficulty of emotional identification $(r=-.596, p=.019)$ and the total score of Alexithymia $(r=-.619, p=.014)$. The family social support sub-scale also had an inverse relationship with Alexithymia's emotional expression difficulty scores $(r=-.609, p=.016)$, difficulty of emotional identification $(r=-.702, p=.004)$ and the total score of Alexithymia $(r=-.72, p=.002)$. The EQR emotional suppression score had a relationship with Alexithymia's emotional expression difficulty score $(r=.654, p=.008)$, and a negative relationship with social support $(r=-.552, p=.033)$.

\section{Discussion}

Recent evidence have highlighted potential bidirectional links between social relationships and inflammation (Eisenberger, Moieni, Inagaki, Muscatell, \& Irwin, 2017; Slavich \& Irwin, 2014). The regions of cerebral release of inflammatory cytokines are sensitized and influence the affective (depressive) state and social behavior. (Slavich \& Irwin, 2014). Given that social support is a well-known buffer of stress reactions (Bowen et al., 2014), it might decrease stress-induced inflammatory reactions. In addition, inflammation can influence relationship processes, as shown by research on sickness behavior (Eisenberger et al., 2017; Slavich \& Irwin, 2014).

Table 1. Psychosocial effects pre-post treatment

\begin{tabular}{|c|c|c|c|c|}
\hline Measure & Pre-Treatment & Post-Treatment & Statistical & Effect Size \\
\hline Anxiety & 12 & 7 & $Z=-1.983^{*}$ & $r=0.3$ \\
\hline Depression & $9.18(3.96)$ & $7.22(4.57)$ & $t_{(21)}=2.776 *$ & $d=0.49$ \\
\hline Social support & $55.36(8.35)$ & $57.40(8.63)$ & $t_{(21)}=-2.46^{*}$ & $d=0.24$ \\
\hline Emotional suppression & $14.95(5.05)$ & $13.04(5.15)$ & $t_{(21)}=2.695$ & $d=0.37$ \\
\hline Cognitive Reassessment & $30.59(6.36)$ & $31.27(6.37)$ & $t_{(21)}=-0.62$ & $d=0.10$ \\
\hline Alexithymia & $20.04(10.33)$ & $17.18(8.62)$ & $t_{(21)}=1.982$ & $d=0.27$ \\
\hline
\end{tabular}

Note: Means, standard deviation, median, and effect size of the psychosocial measures pre-post treatment. The distribution of the anxiety score was not normally distributed, so the Wilcoxon test was used to compare their medians pre-post treatment; the rest of the scores were compared with the statistical test $t$ of student. ${ }^{*} p<.05$. 
Sickness-induced inflammation can directly lead to social withdrawal (Miller, \& Raison, 2016). Eisenberger and colleagues (2017) have proposed that inflammation can also increase sensitivity to positive social processes and foster effective support. By increasing one's sensitivity to positive social resources, individuals stand to benefit more from their relationships during times of need (Muscatell, Eisenberger, Dutcher, Cole, \& Bower, 2016). In fact, the level of IL-6 concentration has been linked to depressive symptomatology. Our results indicate that the proposed treatment lowered the level of IL-6, the depression score and increased the social support score, which is consistent with the study by Miller and Raison (2016).

According to the proposed objectives, it was found that the suggested treatment reduced the number of errors of emotional facial recognition in a meaningful way; It reduced the psychophysiological responses associated with stress, as well as the psychosocial symptomatology of anxiety, depression and emotional suppression, increasing the perception of social support. Although the score of Alexithymia decreased marginally, it is possible that maintaining the training in emotion discrimination and its expression, not only facial, but verbal under appropriate social situations, contributes to increase the effect.

Specializing literature in the deficit of emotional facial recognition has focused on population with psychiatric or neurological disorders and few behavioral rehabilitation programs offer a training in facial recognition and facial emotional expression. The study of Rawdon et al. (2018) investigated the effect of this training on anxiety and depression in adolescents with social anxiety and showed an improvement in the perception of joy, although it failed to reduce anxiety, but found evidence of decrease in depression symptoms.

In relation to the results of Rawdon et al. (2018), our results agree with an effect on reducing depression scores; however, unlike its protocol, our intervention adds the behavioral components of emotional facial reproduction and its muscular deactivation, through relaxation, which allowed the participant to discriminate the activation and deactivation emotional facial, whose psychophysiological effect decreased the respiratory rate (somatic component), and the concentration of IL-6 (inflammatory response), which allowed to decrease the score of anxiety and depression. This effect of relaxation on the decrease in IL-6 and depression agree with those reported by Koh, Lee, Beyn, Chu, \& Kim (2008).

The results of this pilot study show a relationship between IL-6 and emotional facial recognition errors, so training in emotional facial recognition and reproduction may be an intervention option in social skills in patients with a high concentration of IL-6, such as chronic non-communicable diseases (chronic pain, diabetes, among others), and affective disorders and anxious spectrum.

These social skills could be included in the pregraduate and postgraduate programs, as well as in the mental health workforce. Randomized clinical trials can be performed to assess their effect on these and other variables. For example, a clinical application could be established in patients suffering from chronic pain: the presence of pain hinders the discrimination of emotional stimuli with positive valence, like a face of joy, and facilitates the perception of a face with expression of pain (Wieser, Gerdes, Reicherts, \& Pauli, 2014).

The training could be complemented by discrimination of body states, such as the tense body and face and its muscular facial deactivation to retrain the autonomic and immunological nervous system. Among the limitations of this research should be considered the presence of a control group and longitudinal follow-up to assess the psychosocial effect of this group. Additionally, other elements may be considered for the emotional expression program, such as the verbal social skills and body postures (Price \& Harmon, 2015) and to evaluate their biopsychosocial effects, for example, with infrared thermal imaging (Topalidou \& Ali, 2017).

\section{Conflicts of interest}

The authors have no conflicts of interest to declare.

\section{References}

Arango, I., Fresan, A., Brüne, M., \& Muñoz, J. (2014). Evaluación de la capacidad para reconocer la expresión facial de las emociones por parte de residentes de psiquiatría a lo largo de tres años de formación. Salud Mental, 37(6), 455-460.

Berg, H., Ballard, E., Luckenbaugh, D., Nugent, A., Ionescu, D., \& Zarate, C. (2016). Recognition of emotional facial expressions in anxious and nonanxious depression. Comprehensive Psychiatry, 70, 1-8. http://dx.doi. org/10.1016/j.comppsych.2016.06.007

Bollen, J., Trick, L., Llewellyn, D., \& Dickens, C. (2017). The effects of acute inflammation on cognitive functioning and emotional processing in humans: A systematic review of experimental studies. Journal Of Psychosomatic Research, 94, 47-55. http://dx.doi.org/10.1016/j.jpsychores.2017.01.002

Bowen, K.S., Uchino, B.M., Birmingham, W., Carlisle, M., Smith T. W., \& Light, K.C. (2014). The stress-buffering effects of functional social support on ambulatory blood pressure. Health Psychology, 33, 1440-1443. http://dx.doi.org/10.1037/ hea0000005 
Cabello, R., Salguero, J., Fernández-Berrocal, P., \& Gross, J. (2013). A Spanish Adaptation of the Emotion Regulation Questionnaire. European Journal Of Psychological Assessment, 29(4), 234-240. http://dx.doi.org/10.1027/1015$5759 / \mathrm{a} 000150$

Carpenter, L., Gawuga, C., Tyrka, A., Lee, J., Anderson, G., \& Price, L. (2010). Association between Plasma IL-6 Response to Acute Stress and Early-Life Adversity in Healthy Adults. Neuropsychopharmacology, 35(13), 2617-2623. http://dx.doi.org/10.1038/npp.2010.159

Chóliz, M., \& Fernández-Abascal, E. (2012). Recognition of emotional facial expressions: the role of facial and contextual information in the accuracy of recognition. Psychological Reports, 110(1), 338-350. http://dx.doi.org/10.2466/07.09.17. pr0.110.1.338-350

Cohn J, Ambadar Z, \& Ekman P. (2007) Observer-Based Measurement of Facial Expression With the Facial Action Coding System. In: Cohan J., \& Allen J., editors. Handbook Of Emotion Elicitation And Assessment. New York: Oxford University Press, pp. 203 - 221. https://pdfs.semanticscholar. org/eafd/a8a94e410f1ad53b3e193ec124e80d57d095.pdf

Conson, M., Ponari, M., Monteforte, E., Ricciato, G., Sarà, M., Grossi, D., \& Trojano, L. (2013). Explicit recognition of emotional facial expressions is shaped by expertise: evidence from professional actors. Frontiers in psychology, 4, 382. http://dx.doi.org/10.3389/fpsyg.2013.00382

Dimberg, U., Thunberg, M., \& Elmehed, K. (2000). Unconscious Facial Reactions to Emotional Facial Expressions. Psychological Science, 11(1), 86-89. https://doi. org/10.1111/1467-9280.00221

Domínguez-Sánchez, F. (2010). La alegría, la tristeza y la ira. In E. Fernández-Abascal, B. García Rodríguez, M. JiménezSánchez, M. Martín Díaz, \& F. Domínguez, Psicología de la Emoción (1st ed., pp. 280-336). Madrid: Centro de Estudios Ramón Areces.

Durán W. (2007). Validación de la Escala de Alexitimia de Toronto (TAS - 20). Accessed October 4, 2015. http://catarina.udlap. mx/u_dl_a/tales/documentos/lps/weisel_d_m/indice.html

Eisenberger, N. I., Moieni, M., Inagaki, T. K., Muscatell, K. A., \& Irwin, M. R. (2017). In sickness and in health: The coregulation of inflammation and social behavior. Neuropsychopharmacology. Reviews, 42, 242-253. http:// dx.doi.org/10.1038/npp.2016.141

Gola, K., Shany-Ur, T., Pressman, P., Sulman, I., Galeana, E., \& Paulsen, H., Nguyen,L., Wu, T., Adhimoolam, B., Poorzand, P., Miller, B., Rankin, K. (2017). A neural network underlying intentional emotional facial expression in neurodegenerative disease. Neuroimage: Clinical, 14, 672-678. http://dx.doi. org/10.1016/j.nicl.2017.01.016

González Ramírez, M., \& Hernández, R. (2014). Propiedades Psicométricas de la Escala de Apoyo Social Familiar y de Amigos (AFA-R) en una Muestra de Estudiantes. Acta De Investigación Psicológica, 4(2), 1469-1480. http://dx.doi. org/10.1016/s2007-4719(14)70387-4

Hunter, C. A., \& Jones, S. A. (2015). IL-6 as a keystone cytokine in health and disease. Nature Immunology, 16, 448-457. http:// dx.doi.org/10.1038/ni.3153

Kessler, H., Bayerl, P., Deighton, R., \& Traue, H. C. (2002). Facially Expressed Emotion Labeling (FEEL): PC-gestuetzter
Test zur Emotionserkennung. Verhaltenstherapie und Verhaltensmedizin, 23(3), 297-306.

Koelsch, S., Boehlig, A., Hohenadel, M., Nitsche, I., Bauer, K., \& Sack, U. (2016). The impact of acute stress on hormones and cytokines and how their recovery is affected by music-evoked positive mood. Scientific Reports, 6(1). http://dx.doi. org/10.1038/srep23008

Jurado, S., Villegas, M., Méndez, L., Rodríguez, F., Loperena, V., \& Varela, R. (1998). La estandarización del Inventario de Depresión de Beck para los residentes de la ciudad de México. Salud Mental, 21(3), 26-31.

Kalawski, J. P. (2013). Using Alba Emoting ${ }^{\mathrm{TM}}$ to work with emotions in psychotherapy. Clinical Psychology, \& Psychotherapy, 20 (2), 180-187. https://doi.org/10.1002/cpp.790

Koh, K., Lee, Y., Beyn, K., Chu, S., \& Kim, D. (2008). Counterstress effects of relaxation on proinflammatory and antiinflammatory cytokines. Brain, Behavior, and Immunity, 22(8), 1130-1137.http://dx.doi.org/10.1016/j.bbi.2008.06.009

Lazaridou, A., Martel, M., Cahalan, C., Cornelius, M., Franceschelli, O., \& Campbell, C. et al. (2018). The impact of anxiety and catastrophizing on interleukin- 6 responses to acute painful stress. Journal of Pain Research, Volume 11, 637-647. http://dx.doi.org/10.2147/jpr.s147735

Levenson, R., Ekman, P., \& Friesen, W. (1990). Voluntary Facial Action Generates Emotion-Specific Autonomic Nervous System Activity. Psychophysiology, 27(4), 363-384. http:// dx.doi.org/10.1111/j.1469-8986.1990.tb02330.

Liu, Y. Z., Wang, Y. X., \& Jiang, C. L. (2017). Inflammation: The Common Pathway of Stress-Related Diseases. Frontiers in Human Neuroscience, 11, 316. http://dx.doi.org/10.3389/ fnhum.2017.00316

Miller, A. H., \& Raison, C. L. (2016). The role of inflammation in depression: From evolutionary imperative to modern treatment target. Nature Reviews Immunology, 16, 22-34. http://dx.doi. org/10.1038/nri.2015.5

Moieni, M., Irwin, M., Jevtic, I., Breen, E., \& Eisenberger, N. (2015). Inflammation impairs social cognitive processing: A randomized controlled trial of endotoxin. Brain, Behavior, and Immunity, 48, 132-138. http://dx.doi.org/10.1016/j. bbi.2015.03.002

Morales, M.G.E., López, R.E.O., \& Hedlefs, A.M.I. (2010). La psicología de las emociones: La expresión facial como una revelación de la emoción y el pensamiento. México: Trillas.

Muscatell, K.A., Eisenberger, N. L., Dutcher, J.M., Cole, S.W., \& Bower, J. E. (2016). Links between inflammation, amygdala reactivity, and social support in breast cancer survivors. Brain, Behavior, and Immunity, 53, 34-38. http://dx.doi.org/10.1016/j. bbi.2015.09.008

Porges, S. (2001). The polyvagal theory: phylogenetic substrates of a social nervous system. International Journal Of Psychophysiology, 42(2), 123-146. https://doi.org/10.1016/ S0167-8760(01)00162-3

Porges, S. (2003). Social Engagement and Attachment. Annals Of The New York Academy Of Sciences, 1008(1), 31-47. doi: 10.1196/annals.1301.004

Price, T., \& Harmon-Jones, E. (2015). Embodied emotion: the influence of manipulated facial and bodily states on emotive responses. Wiley Interdisciplinary Reviews: Cognitive Science, 6(6), 461-473. http://dx.doi.org/10.1002/wcs.1370 
Prochazkova, E., \& Kret, M. (2017). Connecting minds and sharing emotions through mimicry: A neurocognitive model of emotional contagion. Neuroscience \& Biobehavioral Reviews, 80, 99-114. https://doi.org/10.1016/j.neubiorev.2017.05.013.

Quinn, A., Williams, A., Sivilli, T., Raison, C., \& Pace, T. (2018). The plasma interleukin-6 response to acute psychosocial stress in humans is detected by a magnetic multiplex assay: comparison to high-sensitivity ELISA. Stress, 21(4), 376-381. https://doi.org/10.1080/10253890.2018.1446518

Rawdon, C., Murphy, D., Motyer, G., Munafò, M., Penton-Voak, I., \& Fitzgerald, A. (2018). An investigation of emotion recognition training to reduce symptoms of social anxiety in adolescence. Psychiatry Research, 263, 257-267. http:// dx.doi.org/10.1016/j.psychres.2018.02.023

Ricciardi, L., Visco-Comandini, F., Erro, R., Morgante, F., Bologna, M., \& Fasano, A., Ricciardi, D., Edwards, M., Kilner, J.. (2017). Facial Emotion Recognition and Expression in Parkinson's Disease: An Emotional Mirror Mechanism? PLOS ONE, 12(1), e0169110. http://dx.doi. org/10.1371/journal.pone.0169110

Robles, R., Varela, R., Jurado, S., \& Páez, F. (2001). Versión mexicana del Inventario de Ansiedad de Beck: propiedades psicométricas. Revista Mexicana de Psicología, 0, 211-217.

Rohleder, N., Aringer, M., \& Boentert, M. (2012). Role of interleukin-6 in stress, sleep, and fatigue. Annals of the New York Academy of Sciences, 1261(1), 88-96. http://dx.doi. org/10.1111/j.1749-6632.2012.06634.x

Shafir, T. (2015). Movement - based strategies for Emotion Regulation. In M. Bryant, Handbook on Emotion Regulation (1st ed., pp. 231-249). Nova Science Publishers, Inc. Retrieved from https://www.researchgate.net/profile/Tal_
Shafir/publication/281783372_Shafir_T_2015_Body-based_ strategies_for_emotion_regulation_In_ML_Bryant_Ed_ Handbook_on_Emotion_Regulation_Processes_Cognitive_ Effects_and_Social_Consequences_pp_231-249_Nova_ Science_Publishers_Inc/links/55f84f6908aec948c47ac7cb. pdf

Shiroma, P., Thuras, P., Johns, B., \& Lim, K. (2016). Facial recognition of happiness among older adults with active and remitted major depression. Psychiatry Research, 243, 287291. http://dx.doi.org/10.1016/j.psychres.2016.06.020

Slavich, G. M., \& Irwin, M. R. (2014). From stress to inflammation and major depressive disorder: A social signal transduction theory of depression. Psychological Bulletin, 140, 774-815. http://dx.doi.org/10.1037/a0035302

Srinivasan, R., Golomb, J., \& Martinez, A. (2016). A Neural Basis of Facial Action Recognition in Humans. Journal of Neuroscience, 36(16), 4434-4442. http://dx.doi.org/10.1523/ jneurosci.1704-15.2016

Topalidou, A., \& Ali, N. (2017). Infrared Emotions and Behaviors: Thermal Imaging in Psychology. International Journal of Prenatal, \& Life Sciences, 01(01), 65-70. http://dx.doi. org/10.24946/ijpls.20.17.0101.110704

Voorhees, J., Tarr, A., Wohleb, E., Godbout, J., Mo, X., Sheridan, J..., \& March, C. (2013). Prolonged Restraint Stress Increases IL-6, Reduces IL-10, and causes persistent depressive-like behavior that is reversed by recombinant IL-10. Plos ONE, 8(3), e58488. http://dx.doi.org/10.1371/journal. pone. 0058488

Wieser, M., Gerdes, A., Reicherts, P., \& Pauli, P. (2014). Mutual influences of pain and emotional face processing. Frontiers in Psychology, 5 http://dx.doi.org/10.3389/fpsyg.2014.01160 
